\title{
Arylsulfatase A pseudodeficiency in healthy Brazilian individuals
}

\section{C.G. Pedron ${ }^{1,2}$ P.A. Gaspar ${ }^{1}$, \\ R. Giugliani $i^{1,3}$ and \\ M.L.S. Pereira ${ }^{1,2}$}

\author{
${ }^{1}$ Serviço de Genética M édica, Hospital de Clínicas de Porto Alegre, \\ ${ }^{2}$ Departamento de Bioquímica, Instituto de Ciências Básicas da Saúde, \\ and ${ }^{3}$ Departamento de Genética, Instituto de Biociências, \\ Universidade Federal do Rio Grande do Sul, Porto Alegre, RS, Brasil
}

\begin{abstract}
Correspondence
R. Giugliani

Serviço de Genética Médica

Hospital de Clínicas de

Porto Alegre

Rua Ramiro Barcelos, 2350

90035-003 Porto Alegre, RS

Brasil

Fax: + 55-51-316-8010

E-mail: rgiugliani@ hcpa.ufrgs.br

Research supported by CNPq, CAPES, FAPERGS, FIPE-HCPA, PRO PESP-

UFRGS and PRONEX

(No. 76.97.1025.00). C.G. Pedron

was supported by CAPES, R. Giugliani

and M.L.S. Pereira were supported by

CNPq.
\end{abstract}

Received December 3, 1998

Accepted April 19, 1999

\section{Abstract}

Molecular alterations associated with arylsulfatase A pseudodeficiency (ASA-PD) were characterized by PCR and restriction endonuclease analysis in a sample of healthy individuals from Brazil. ASA activity was also assayed in all subjects. Two individuals homozygous for the $\mathrm{N} 350 \mathrm{~S}$ and $1524+95 \mathrm{~A} \rightarrow \mathrm{G}$ mutations were detected, corresponding to a frequency of $1.17 \%$ ( 4 of 324 alleles). The individual frequency of the N350S mutation was $20.7 \%$ ( 71 of 342 alleles) and $7.9 \%$ (27 of 342 alleles) for the $1524+95 \mathrm{~A} \rightarrow \mathrm{G}$ mutation. The frequency of the ASA-PD allele in our population was estimated to be $7.9 \%$. This is the first report of ASA-PD allele frequency in a South American population. In addition, the methods used are effective and suitable for application in countries with limited resources. All patients with low ASA activity should be screened for ASA-PD as part of the diagnostic procotol for metachromatic leukodystrophy.

\section{Introduction}

Arylsulfatase A (ASA, EC 3.1.6.1) is a lysosomal hydrolase that catalyzes the first step in the degradation of cerebroside-3-sulfate, a glycosphingolipid found mainly in the white matter of the central nervous system and in the peripheral nerves (1). The gene coding for human arylsulfatase A maps to the long arm of chromosome 22 and spans $3.2 \mathrm{~kb}$ of genomic DNA divided into eight exons. ASA cDNA hybridizes to three different mRNA species and is predicted to code for a protein of 507 amino acids (2).

Mutations in the ASA gene can lead to ASA deficiency, which is associated with two clinical conditions: metachromatic leu-

\section{Key words}

- Arylsulfatase A

- Pseudodeficiency

- Metachromatic

leukodystrophy kodystrophy (MLD) and arylsulfatase A pseudodeficiency (ASA-PD). MLD is a rare lethal neurodegenerative disorder which is inherited as an autosomal recessive trait. MLD patients store sulfatide in their tissues, particularly in the central nervous system. The disease is divided into three clinical forms according to age of onset. MLD-associated mutations have been determined and extensively studied in affected populations (1).

ASA-PD affects healthy individuals, who also show low ASA activity but not sulfatide storage or high excretion of sulfatides in urine. ASA-PD is also caused by alterations in the ASA gene, where A to G transitions are responsible for both an asparagine to serine substitution in exon 6 (termed N350S) 
and for the loss of the first polyadenylation signal downstream from the stop codon (termed $1524+95 \mathrm{~A} \rightarrow \mathrm{G}$ ) (3). After characterization of these alterations, simple methods for detecting carriers of these alterations by PCR were developed $(4,5)$.

The identification of the molecular basis for ASA-PD permitted the estimate of the frequency of the PD allele in different populations which was found to range from 6 to $23 \%(3,6-9)$. The high frequency of the ASA$\mathrm{PD}$ allele in the general population requires accurate detection of individuals carrying the allele in families at risk for MLD, since the ASA-PD allele is also found in MLD patients (10). The detection of sulfatide storage, which would confirm MLD, is a timeconsuming assay. Furthermore, recent data indicate that the detection of the ASA-PD allele is not only important for families at risk for MLD but can be useful for evaluating a possible risk factor for dementia (11).

The data presented here are the first report of ASA-PD allele frequencies in a South American population. We have evaluated the frequency of the N350S and the $1524+95 \mathrm{~A} \rightarrow \mathrm{G}$ mutations in a healthy Brazilian population, and compared the genotypes determined to ASA activity levels in all individuals.

\section{Material and Methods}

\section{Subject samples}

The study was approved by the hospital committee on ethical practice and research. Each individual was previously informed of the aims of the study and asked to sign a consent form before sample collection. Blood samples were collected from 171 healthy and unrelated individuals ( 76 males and 95 females) for both leukocyte preparation (for biochemical analyses) and DNA extraction (for molecular detection of ASA-PD alterations). The ethnic background of the individuals was mixed (predominantly Cauca- sians) and representative of the population where the study was carried out.

\section{Leukocyte preparation and biochemical analysis}

Leukocytes (WBC) were isolated from $10 \mathrm{ml}$ heparinized blood by the dextran sedimentation method (12) and stored at $-40^{\circ} \mathrm{C}$. Each WBC pellet was resuspended in $500 \mu 1$ deionized water and disrupted by rapid freezing and thawing procedures. Protein contents were determined according to standard methods (13). ASA activity was measured using 4-nitrocatechol sulfate as substrate (14). B-Galactosidase was assayed as a reference enzyme and arylsulfatase B (ASB) activity was measured in samples with low ASA activity to rule out multiple sulfatase deficiency.

\section{DNA extraction and molecular analysis}

Genomic DNA was prepared by standard procedures (15). Fragments of interest were amplified by PCR and mutations detected by digestion with restriction endonucleases (5).

\section{Statistical analyses}

ASA activity data were analyzed by ANOVA and post-hoc comparisons were made using the Duncan and Bonferroni multiple range tests.

\section{Results and Discussion}

DNA samples were screened for the $\mathrm{N} 350 \mathrm{~S}$ and the $1524+95 \mathrm{~A} \rightarrow \mathrm{G}$ mutations and the results obtained are shown in Figure 1. Samples were divided into five groups (A to E) on the basis of these results. In addition to the molecular data, the ASA activities of each individual were determined and the ranges can be seen in Table 1. ASA activities were measured in duplicate and mean values were used to calculate ranges in each group. 
Within each group, samples were subdivided according to gender. A relationship between ASA activity and the different genotypes detected was established and is shown in Figure 2.

The detection of each specific mutation showed that the N350S mutation was present in 71 of the 342 alleles tested, giving a frequency of $20.7 \%$, while the $1524+95 \mathrm{~A} \rightarrow \mathrm{G}$ mutation was found in 27 of the 342 alleles analyzed, representing $7.9 \%$ of the study population.

These data demonstrate the detection of molecular alterations associated with ASA-
PD in a healthy Brazilian population. Patient groups $\mathrm{C}$ and $\mathrm{E}$, which included individuals carrying the $1524+95 \mathrm{~A} \rightarrow \mathrm{G}$ mutation, showed lower ASA activities than the other groups. The ASA activities of individuals from group $\mathrm{E}$ were similar to the activities found in MLD patients in our laboratory. These results confirm the difficulty of distinguishing individuals who are homozygous for the ASA-PD allele from MLD patients by biochemical methods alone. This is of considerable importance when prenatal diagnosis must be carried out solely by enzyme assay. The storage of sulfatides, which would

B

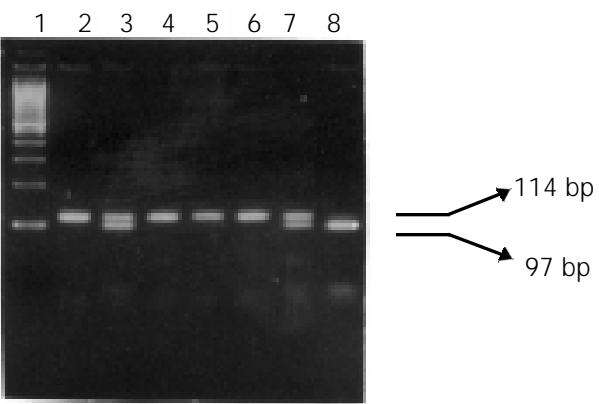

Figure 1 - Detection of the N350S and 1524+95A $\rightarrow$ G mutations. A) Detection of N350S mutation: DNA was amplified by PCR using primers ASA 6i-5' (5' TTGATGGCGAACTGAGTGAC 3') and ASAp 6i-3' (5' CAGTGCAGG AGGCACTGAGG $3^{\prime}$ ), products digested with Bsrl and fractionated on $2.5 \%(\mathrm{w} / \mathrm{v})$ agarose gel. Lanes 1 and 3 are homozygotes for the normal sequence; lanes 2 and 4 are heterozygous individuals; lane 5 is a 100-bp DNA ladder. B) Detection of $1524+95 A \rightarrow G$ mutation. DNA was amplified by PCR using primers ASA E-5' $\left(5^{\prime}\right.$ GGTITGTGCCTGATAACTTA 3') and ASAp 8i-3' (5' TTCCTCATTCGTACCACAGG 3'), products digested with Ddel and separated on 3\% (w/v) agarose gel. Lane 1 is a 100-bp DNA ladder; lanes 2, 4, 5 and 6 are homozygotes for the normal sequence; lanes 3 and 7 are heterozygous individuals, lane 8 is an individual homozygous for the mutant sequence.

Table 1 - Genotypes and ASA activity in different groups of the study population.

a: -/- Indicates homozygotes for the normal sequence; +/- indicates heterozygotes; +/+ indicates homozygotes for the mutant sequence. b: ASA activities are reported as $\mathrm{nmol} \mathrm{h}^{-1} \mathrm{mg}_{\text {protein-1 }}{ }^{-1}$ SD $=$ Standard deviation. ${ }^{*} \mathrm{P}<0.05$ compared to groups $\mathrm{A}$ and $\mathrm{B}$ (ANOVA).

\begin{tabular}{|c|c|c|c|c|c|c|}
\hline \multirow[t]{2}{*}{ Group } & \multicolumn{2}{|c|}{ Genotypes $^{a}$} & \multirow[t]{2}{*}{ No. of subjects } & \multicolumn{3}{|c|}{ ASA activityb } \\
\hline & N350S & $1524+95 A \rightarrow G$ & & Range & Mean & SD \\
\hline A & $-1-$ & $-1-$ & 104 & $5.6-28.6$ & 15.5 & 4.3 \\
\hline B & $+/-$ & $-1-$ & 40 & $8.3-22.8$ & 14.6 & 3.9 \\
\hline C & $+/-$ & $+/-$ & 23 & $4.5-19.5^{*}$ & 9.0 & 3.4 \\
\hline D & $+/+$ & $-1-$ & 2 & 8.4 and 21.8 & - & - \\
\hline $\mathrm{E}$ & $+/+$ & $+/+$ & 2 & 0.9 and 1.5 & - & - \\
\hline
\end{tabular}


Figure 2 - ASA activity in samples from each group. Groups A, B, $C, D$ and $E$ refer to the genotypes identified in Table 1.

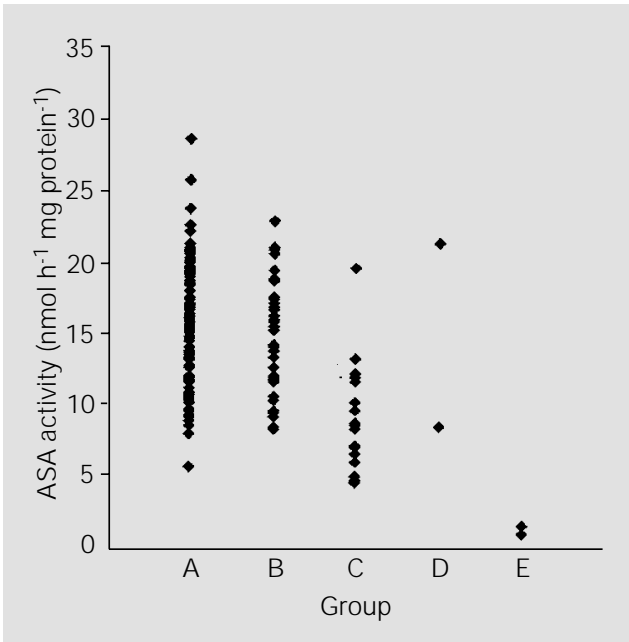

confirm a diagnosis of MLD postnatally, is time-consuming and difficult.

Individuals from group D showed a wide difference in their ASA values and these results were confirmed by two independent assays and reported as the mean value for samples analyzed in duplicate. Therefore, the difference detected is real and shows two extremes of the range. In addition, the values can be compared to the range determined in samples from group B, who share the same molecular alteration (N350S mutation).

When the ASA activities obtained for samples from individuals of different gender within groups $\mathrm{A}, \mathrm{B}$ and $\mathrm{C}$ were compared statistically no difference was observed (data not shown). In addition, when groups A, B and $C$ were compared, group $C$ was found to be different from groups $\mathrm{A}$ and $\mathrm{B}$. This analysis confirms data from previous studies which showed that, although the ASA-PD allele carries 2 mutations in the ASA gene, lower ASA activity is primarily the result of the $1524+95 \mathrm{~A} \rightarrow \mathrm{G}$ mutation (3).

The overall frequencies of the ASA-PD mutations in our population were $20.7 \%$ (71 of 342 alleles) for the N350S mutation and $7.9 \%$ (27 of 342 alleles) for the $1524+95 \mathrm{~A} \rightarrow \mathrm{G}$ mutation. Since in most cases the $1524+95 \mathrm{~A} \rightarrow \mathrm{G}$ mutation occurs together with the N350S mutation, we can deduce that frequency of the ASA-PD allele in the study population is $7.9 \%$, although a test for the presence of both mutations in the same chromosome was not performed. This frequency lies at the lower end of the frequency range reported for other populations. The subjects were of mixed ethnic origin, although there was a predominance of Caucasian ancestors.

The methods used in this study allowed us to determine the frequency of ASA-PDassociated mutations in our population and to establish a control range for ASA activity in healthy individuals who do not carry ASAPD-associated mutations (group A). These methods used are effective and easily performed in countries with limited resources. This is important since all patients with low ASA activity should be screened for ASAPD mutations before a diagnosis of MLD is confirmed and submitted to biochemical investigation complemented by the measurement of urinary sulfatides.

\section{Acknowledgments}

The authors are grateful to all volunteers who kindly provided the samples used in this study. The authors would also like to thank Dr. A. Harris for helpful discussion.

\section{References}

1. Kolodny EH \& Fluharty LA (1995). Metachromatic leukodystrophy and multiple sulfatase deficiency: sulfatase lipidosis. In: Scriver RC, Beaudet LA, Sly SW \& Valle $D$ (Editors), The Metabolic Basis of Inherited Disease. 7th edn. McGraw-Hill, New York, 2693-2740.
2. Barth $M L$, Fensom A \& Harris A (1994). The arylsulphatase $A$ gene and molecular genetics of metachromatic leucodystrophy. J ournal of Medical Genetics, 31: 663666.

3. Gieselmann V, Polten A, Kreysing J \& von Figura K (1989). Arylsulfatase A pseudo- deficiency: loss of a polyadenylation signal and $\mathrm{N}$-glycosylation site. Proceedings of the National Academy of Sciences, USA, 86: 9436-9440.

4. Gieselmann $\vee$ (1991). An assay for the rapid detection of the arylsulfatase $A$ pseudodeficiency allele facilitates diagno- 
sis and genetic counselling for metachromatic leukodystrophy. Human Genetics, 86: 251-255.

5. Barth ML, Ward C, Harris A, Saad A \& Fensom A (1994). Frequency of arylsulphatase A pseudodeficiency-associated mutations in a healthy population. J oumal of Medical Genetics, 31: 667-671.

6. Salamon MB, Christensen E \& Schwartz $M$ (1994). Searching for mutations in the arylsulphatase A gene. J ournal of Inherited Metabolic Disease, 17: 311-314.

7. Nelson PV, Carey WF \& Morris CP (1991). Population frequency of arylsulfatase $A$ pseudo-deficiency allele. Human Genetics, 87: 87-88.

8. Chabas A, Castellvi S, Bayes M, Balcells S, Grinberg D \& Vilageliu L (1993). Frequency of arylsulphatase A pseudodefi- ciency allele in the Spanish population. Clinical Genetics, 44: 320-323.

9. Zlotogora J, Furman-Shaharabani $Y$, Goldenfum S, Winchester B, von Figura K \& Gieselmann V (1994). Arylsulfatase A pseudodeficiency: a common polymorphism which is associated with unique haplotype. American J ournal of Medical Genetics, 15: 146-150.

10. Barth ML, Fensom A \& Harris A (1993). Missense mutations in the arylsulphatase A genes of metachromatic leukodystrophy patients. Human Molecular Genetics, 12: 2117-2121.

11. Philpot $M$, Lewis $K$, Pereira ML, Ward $C$, Holmes C, Lovestone S, Fensom A \& Seller M (1997). Arylsulphatase A pseudodeficiency in vascular dementia and Alzheimer's disease. Neuroreport, 8:
2613-2616.

12. Skog AW \& Beck SW (1956). Studies on the fibrinogen, dextran and phytohemagglutinin methods of isolation leucocytes. Blood, 11: 436-454.

13. Lowry HO, Rosebrough J N, Farr LA \& Randall RJ (1951). Protein measurement with Folin phenol reagent. J ournal of Biological Chemistry, 193: 265-275.

14. Lee-Vaupel M \& Conzelmann E (1987). A simple chromogenic assay for arylsulphatase A. Clinica Chimica Acta, 164: 171180.

15. Miller AS, Dykes DD \& Polesky FH (1988). A simple salting out procedure for extracting DNA from human nucleated cells. Nucleic Acids Research, 16: 1215. 